\title{
Nationwide Awareness Campaign and Call for Dental Screening for HHT in Germany
}

Urban W. Geisthoff

Universitätsklinikum Gießen und Marburg - Standort Marburg: Universitatsklinikum Giessen und Marburg - Standort Marburg

Frank Hölzle

Universitätsklinikum Aachen: Universitatsklinikum Aachen

Boris A. Stuck

Universitätsklinikum Gießen und Marburg - Standort Marburg: Universitatsklinikum Giessen und Marburg - Standort Marburg

Jochen Jackowski

Witten/Herdecke University: Universitat Witten/Herdecke

Catherine Hand Goetz

Arkansas State University - Newport

Christina Grabowski

Morbus Osler Selbsthilfe e.V.

Freya Droege ( $\nabla$ freya.droege@uk-essen.de)

University Hospital Essen: Universitatsklinikum Essen https://orcid.org/0000-0001-8811-507X

\section{Research}

Keywords: hereditary haemorrhagic telangiectasia, awareness campaign, dental screening

Posted Date: September 23rd, 2021

DOI: https://doi.org/10.21203/rs.3.rs-919272/v1

License: (c) (i) This work is licensed under a Creative Commons Attribution 4.0 International License. Read Full License 


\section{Abstract}

Background: HHT is a rare, systemic, inherited disorder in which patients suffer from telangiectasias, especially of the facial skin, lips and oral mucosa, as well as visceral vascular malformations (VM). The diagnosis of HHT is often delayed for decades. However, early detection of VMs can reduce morbidity and mortality.

Methods: In 2018 a nationwide awareness campaign addressing all dentists in Germany consisted of one published article and two reminders about $\mathrm{HHT}$. As a proxy for the effectiveness of the campaign, researchers measured the number of firsttime inquiries from patients and physicians about HHT documented by the German HHT self-help group from September 2016 until September 2019.

Results: A total of 411 first contacts with the German self-help group were documented, mainly via internet platforms (internet forum $(n=130)$ and Facebook ${ }^{\circledR}(n=189)$ ). For $9 \%$ of those patients $(n=36 / 411)$ the physician or dentist (physician: ( $n=31 / 36,86 \%$; dentist: $n=5 / 36,14 \%$ ) informed patients about the disease HHT and the self-help group. Before publishing the first article about HHT no dentist referred patients to the German self-help group; afterwards, 5 patients received information about $\mathrm{HHT}$ from their dentist and contacted the patient organization for the first time. After each publication in June, September and December 2018 the number of new contacts increased. Contacts via phone and e-mail had the highest relative increase.

Conclusions: The repeated call for dental screening for HHT in Germany lead to increased awareness of this rare disease; more patients with possible HHT received information about the condition. The authors conclude that targeted campaigns may contribute to a shorter diagnostic latency resulting in increased quality of life and life expectancy in HHT.

Clinical Trials.gov ID: CT03549949

\section{Background}

Hereditary haemorrhagic telangiectasia $(\mathrm{HHT})$ is a systemic, autosomal dominant, inherited disorder resulting in vascular malformations. With an estimated prevalence of 1-2 individuals per 10.000 the disease is a "relatively frequent" rare disorder $[1,2]$. Patients suffer from recurrent bleedings and problems arising from blood shunting due to visceral vascular malformations. Most patients develop recurrent epistaxis and multiple typical telangiectases of the skin or mucosa, in particular on their face, tongue, and lips (Fig. 1). Visceral vascular manifestations most commonly affect patients' lungs, livers, and brains [3]. Pulmonary arteriovenous malformations (PAVMs) can lead to disturbed filter function of the lungs resulting in abscesses and infarctions of visceral organs like the brain, liver and spleen [4-7]. Therefore, in patients with likely HHT, screening for PAVMs is recommended [8, 9]. The diagnosis of HHT is based on genetic testing and / or the International Clinical Diagnostic Criteria, also known as the Curaçao Criteria. Genetic testing can reveal the diagnosis HHT in most cases but not all disease-causing mutations have been detected [10]. Using the Curaçao Criteria based on patients' family history and the history of epistaxis, telangiectasia and visceral lesions the diagnosis HHT can be established. The presence of at least three out of these four clinical criteria is required in order to diagnose HHT $[3,8]$.

German public health insurances recommend that every adult should visit a dentist at least once a year. To reinforce this recommendation, a bonus system has been established: persons following this recommendation receive higher reimbursement in case of dental repair [11]. Therefore, many Germans (70\%) follow this recommendation [12].

Dentists, as health care professionals, routinely examine the mucosa of the mouth. The detection of typical telangiectases on the patients' oral mucosa and perioral skin during these examinations is likely. By asking additional questions about the family history and recurrent epistaxis the diagnosis of HHT could be considered. In this study the results of a nationwide German HHT awareness campaign and call for dental screening were analysed. 
Previous studies have shown that both early HHT diagnosis and screening for pulmonary involvement, at least, reduced morbidity and mortality in patients with HHT. Referral to an interdisciplinary centre specialized in HHT is advantageous for these tasks $[13,14]$. Patients with HHT and pulmonary arteriovenous malformations (and those where this has not been screened yet) should be informed about the recommendation to use an antibiotic prophylaxis for certain medical procedures [15-17]. This important information was published in articles and reminders for dentists and was further distributed via special patient cards containing this information by the German HHT patient organization. Adoption of these measures by patients with HHT can help prevent complications such as strokes and abscesses [8], which was a major goal of our awareness campaign.

\section{Results}

Between September 2016 and September 2019, a total of 411 first contacts were documented by the German HHT self-help group via internet platforms (internet forum $(n=130)$, Facebook $\left.{ }^{\circledR}(n=189)\right)$, phone $(n=45)$, and e-mail $(n=43 ;$ Fig. 2$)$.

In 91 cases $(91 / 411,22 \%)$ the source of information about the self-help group was known: in 36 cases (36/91, 40\%) doctors - mostly general practitioners - informed patients with possible HHT about the self-help group and patients received information about the disease HHT (Fig. 3). 48\% of the patients $(n=44 / 91)$ did independent internet research about HHT, 9 patients $(9 / 91,10 \%)$ were informed by family members, and 2 patients $(2 / 91,5 \%)$ by friends and members of another selfhelp group (pulmonary hypertension), 1 patient read an article about HHT (1/91, 1\%) [18].

A total of 187 contacts to the self help group were made between September 2016 and May 2018 (187/411, 45\%) before the first dental awareness campaign publication. 7 of those contacts were via phone or e-mail $(7 / 187,4 \%)$. After each publication in June, September, and December 2018 the number of contacts increased. Contacts via phone and e-mail (these communication options were recommended in the publications) had the highest relative increase (number of contacts after 06/2018 divided by number of contacts between 9/2016 and 9/2019): all communication channels: 222/411, 54\%; phone: 40/43, 93\%; e-mail: 39/43, 91\%; internet forum: 31/130, 24\%; Facebook®: 108/189, 57\%; (Fig. 34).

\section{Discussion}

To our knowledge this study describes the first awareness campaign for HHT based on the inclusion of dentists. Every year more than $70 \%$ of the German population receive a professional tooth cleaning and examination by their dentists as it is supported by the German public health insurances $[19,20]$. Therefore, our approach had the potential for a nationwide population-based campaign. In HHT over $80 \%$ suffer from visible symptoms, like muco-/cutaneous telangiectasia, [3, 2123] which could be detected by their dentists. Additionally, most patients and affected relatives suffer from recurrent nosebleeds, which can easily be assessed by taking a history directed specifically at these points. The presence of telangiectases, nosebleeds and/or a positive family history are sufficient to raise suspicion for HHT in the setting of a dental practice resulting in the appropriate referral for further evaluation. Early diagnosis and treatment achieved - like in this case through dental screenings - can lead to improved quality of life for HHT patients [14, 24].

The results of the awareness campaign demonstrated a positive effect: our nationwide dental awareness campaign was associated with a higher frequency of persons contacting the self-help group for the first time. However, the $10 \%$ increase in contacts for an equivalent time interval seems to be relatively small (187 first contacts for the period from September 2016 to May 2018 in comparison to 222 contacts for the period from July 2018 to September 2019). Various explanations exist for the limited impact of the campaign. Our approach targeted dentists. In Germany, dentists normally do not write referrals which may have contributed to the limited effect. Only $9 \%$ of patients indicated that they were informed by their dentists or other physicians on the possibility of HHT. Before the campaign, no dentist referred patients to the German self-help group; afterwards, at least 5 patients received information about HHT by their dentists and mentioned this when they contacted the patient organization for the first time. It is probable that this effect was related to the awareness campaign, which we interpreted as a limited success. However, it is interesting that $44 \%$ of patients stated that they were informed mainly by their 
general practitioners and only $14 \%$ by dentists. A higher rate of referrals by dentists was expected. The authors were not able to identify the reason for this but one possibility is that dentists first referred to the general practitioner who then recommended that patients contact the self-help group.

Diagnosing rare diseases is challenging, as they are numerous and diverse in presentation. Therefore it is appropriate, that general practitioners and dentists have only limited knowledge of such diseases [25]. About 5000 rare diseases are known of which 700 involve dental, oral or craniofacial pathologies [26]. Given that an oral mucosal examination is a relatively simple and inexpensive screening tool, the World Dental Federation states that a systematic examination of the oral mucosa should be part of every dental examination procedure [27]. HHT is an autosomal inherited disease inflicting female and male patients of various ages [28]. In Germany, dentists are the only primary health-care professionals treating patients of all ages and sexes. They are providers of primary oral healthcare and therefore essential gatekeepers for the management of patients who may have oral manifestations of systemic diseases, As such, they are often likely to be the first clinicians to observe such abnormalities [24, 29]. However, another study analysed the identifying rate of early oral cancer in the general dental practice and came to the conclusion that this is of limited effectiveness. Diagnostic screening systems also depend on qualitative factors - on primary health-care professionals using their discretion and clinical judgement for the screening process to work effectively. Although thorough screening might be challenging from a practical and economical point of view, clinical judgement should be encouraged in order to detect unexpected or rare diseases, like HHT [30]. As mentioned above, we identified specific limitations to our approach with dentists. An consideration is that dentists are flooded with information and, even though the article was published in an important set book, this was only read by a limited number of dentists. We plan to increase awareness during future studies by asking the patients of self-help groups to print out the articles of the awareness campaigns and to present them to their dentists during their next visits.

Awareness campaigns for rare diseases like HHT are necessary in order to reduce the diagnostic latency and improve the medical care of these patients [31, 32]. The German patient self-help group and different HHT centres and hospitals have been working toward heightened awareness of $\mathrm{HHT}$ in the general population and among healthcare professionals over the past years. However, the effect was limited and further measures seemed necessary [33]. In general, many problems in treating patients with rare diseases result from the lack of awareness or experience among healthcare professionals, low motivation, and barriers to changing practice or policies. One approach to increase awareness of and familiarity with rare diseases in healthcare is to target the postgraduate education of gatekeeper care providers, like dentists or primary care physicians. The goal of this education would be to help these providers differentiate rare diseases amidst the backdrop of the general population. Such education might be especially effective if it focuses on recognizable, core warning signs of rare diseases instead of on in-depth information. In this way, physicans might be more easily able to detect divergent patterns of diseases through their "gut feeling" pattern recognition [34]. Health promotion activities that focus on large populations such as smoking cessation campaigns may affect the health of many individuals which encourages engagement by primary care physicians and government agencies. However, mainly due to the lack of exposure or awareness of primary care providers or politicians the incentive to change practice or policy may be limited for rare diseases [35]. The "Shit Happens" campaign is an example of a parents-oriented research project for patients with the rare condition Hirschsprung's disease. The campaign demonstrated that social media can be a powerful and responsive tool to connect families with rare diseases [36].

To tailor the HHT awareness campaign to dentists as the target audience, we studied approaches taken by earlier campaigns targeting dentists. Two awareness campaigns, one in Brazil and the other in Florida, were implemented in order to improve the prevalence of hepatitis $B$ vaccination among dentists and to inform dentists about diagnosing and treating patients with temporomandibular disorders. The campaigns were mainly based on online tools and resulted in low response rates amongst dentists $[37,38]$. Therefore, we developed a different approach by publishing repeated articles in a set book for all dentists in Germany. In our awareness campaign a case report about HHT together with instructions about disease management of HHT were published online and in print in the journal of the German dental association and the Federal Association of Fund Dentists of Germany which every dentist receives in Germany. This journal is a set book for all dentists 
in Germany with a total circulation of 77621 copies in 2017. After publication of the article the number of first contacts to the German self-help group via phone calls and emails increased, especially when comparing the time periods two months before and after the first publication. Only these two means of communication were suggested in the publication, and subsequently, the increase in these routes were higher than in other channels like Facebook® or internet inquiries, suggesting that the rise in new contacts might be associated with our campaign. Interestingly, almost half of the patients answering to this question did an internet research about HHT and the German self-help group to access information on the disease. This underscores the fact that the internet has become a very popular source of health-related information for patients [39]. Likewise, many healthcare professionals use web-based tools for obtaining health-related information; however, defective synthesis of the available information can lead to diagnostic error [40].

Data was provided by the German HHT self-help group. Due to technical problems the documentation of the different communication channels for the whole period is only complete for first-time contacts by phone. It should be noted that another limitation of the study was that neither patients' details (i.e. sex, age, clinical symptoms) nor a follow up of completed screening or necessary therapies could be documented due to data protection regulations. However, the cooperation of the self-help group for HHT and medical professionals during this study demonstrates the important role that patient involvement plays in the healthcare system [41, 42].

The article on HHT was published in June 2018. On the beginning of July 2018 , the new website of the German HHT selfhelp group was launched. Therefore, the effect of the new homepage might have been a confounding factor. However, a new website several years ago did not increase number of phone contacts at that time.

The development of a table showing oral manifestations and basic information, not just for HHT but also for other rare diseases, will be a task for our future work in order to facilitate the diagnostic process and to inform dentists about treatment options of different rare diseases.

\section{Conclusion}

This study demonstrates that a nationwide awareness campaign and call for dental screening for HHT in Germany lead to an increased number of persons with possible HHT being informed about the disease. This might contribute to early diagnosis and treatment in HHT and consequently improvements in morbidity and mortality among HHT patients.

\section{Methods}

From September 2016 until September 2019 the German HHT self-help group documented all first inquiries from patients and physicians about HHT. The self-help group was contacted directly via e-mail or phone. Additionally, a board member of the German HHT self-help group provided data from an internet forum (https://www.morbusosler.info/) and a closed Facebook® group on HHT (https://www.facebook.com/groups/1889282361305763/).

In June 2018, a case report of a patient with HHT and PAVM developing a liver abscess after professional tooth cleaning together with an explanation and instruction on disease management in HHT was published in the journal of the German dental association and the Federal Association of Fund Dentists of Germany [15]. This journal is distributed to all dentists in Germany and is a set book for them. In 2017 it had a total circulation of 77,261 [43]. Three and six months later a reminder was published in the same journal $[16,17]$. In these three articles, dentists were asked to pay attention to typical telangiectases of the oral mucosa and facial skin and - upon discovery - to ask the patients if they or other relatives have nosebleeds. If HHT is suspected, it was advised to recommend that the patient get in contact with a medical centre to clarify a potential diagnosis. The self-help group was recommended as a way for patients to find the appropriate medical centre. The phone number and email address of the self-help group were given for this purpose. Technical problems led to a loss of documentation on the number of e-mails the German self-help group received from September 2016 to April 2018, so that 
only the email-documentation from April 2018 until September 2019 was available for analysis. However, the documentation for phone calls was complete.

Data on type and time of contacts were collected by the German self-help group and sent to our research group in an anonymized form. Statistical analyses were performed with Microsoft Excel (Microsoft Cooperation, version 16.0).

\section{Abbreviations}

$\mathrm{HHT}=$ hereditary hemorrhagic telangiectasia

$\mathrm{PAVM}=$ pulmonary arteriovenous malformations

$\mathrm{N}=$ number of patients / contacts

\section{Declarations}

Ethics approval and consent to participate: Data on type and time of contacts were collected by the German self-help group and sent to the author group in an anonymized form, so that no ethics approval was necessary. The study was performed in accordance with the Declaration of Helsinki and registered by Clinical Trials.gov (Clinical Trials.gov ID: CT03549949).

Consent for publication: Not applicable.

Availability of data and materials: The datasets used and/or analysed during the current study are available from the corresponding author on reasonable request.

Authors' contributions: UG, CG and FD have made substantial contributions to the conception of the work, the acquisition, analysis, and interpretation of data. UG and FD have drafted the work. All authors have approved the submitted version (and any substantially modified version that involves the author's contribution to the study) and all authors have agreed both to be personally accountable for the author's own contributions and to ensure that questions related to the accuracy or integrity of any part of the work, even ones in which the author was not personally involved, are appropriately investigated, resolved, and the resolution documented in the literature.

Competing interests: Urban Geisthoff is consulting and collaborating with patient organizations for HHT (www.hht.org, www.morbus-osler.de). Freya Droege is supported by the University Medicine Essen Clinician Scientist Academy UMEA Clinician Scientist Program and received financial support from the Stiftung Universitätsmedizin Essen. There are no other relevant conflicts of interest or disclosures.

Funding: This research did not receive any specific grant from funding agencies in the public, commercial, or not-for-profit sectors.

\section{Acknowledgements}

The authors are grateful to the German self-help group for administration of the inquiries from patients and physicians and thank Ralf Schmiedel for providing data about the internet forum and Facebook ${ }^{\circledR}$ group.

Part of this study was presented at the $12^{\text {th }}$ International Scientific HHT meeting in Dubrovnik, Croatia 08.-11.6.2017, the annual meeting of the German society for otorhinolaryngology in Berlin, Germany 30.05.-01.06.2019, and has been published as abstract in Laryngorhinootologie 2019; 98(S 02): 362-363; doi: 10.1055/s-0039-1686721.

We acknowledge support by the Open Access Publication Fund of the University of Duisburg-Essen. 


\section{References}

1. M. Dakeishi, T. Shioya, Y. Wada, T. Shindo, K. Otaka, M. Manabe, J. Nozaki, S. Inoue, A. Koizumi, Genetic epidemiology of hereditary hemorrhagic telangiectasia in a local community in the northern part of Japan, Hum Mutat 19(2) (2002) $140-8$.

2. A.D. Kjeldsen, P. Vase, A. Green, [Hereditary hemorrhagic telangiectasia. A population-based study on prevalence and mortality among Danish HHT patients], Ugeskr Laeger 162(25) (2000) 3597-601.

3. C.L. Shovlin, A.E. Guttmacher, E. Buscarini, M.E. Faughnan, R.H. Hyland, C.J. Westermann, A.D. Kjeldsen, H. Plauchu, Diagnostic criteria for hereditary hemorrhagic telangiectasia (Rendu-Osler-Weber syndrome), American journal of medical genetics 91(1) (2000) 66-7.

4. J. Bodilsen, Hereditary haemorrhagic telangiectasia and pulmonary arteriovenous malformations in brain abscess patients: a nationwide, population-based matched cohort study, Clin Microbiol Infect (2020).

5. A.D. Kjeldsen, P.M. Torring, H. Nissen, P.E. Andersen, Cerebral abscesses among Danish patients with hereditary haemorrhagic telangiectasia, Acta Neurol Scand 129(3) (2014) 192-7.

6. C.L. Shovlin, R. Condliffe, J.W. Donaldson, D.G. Kiely, S.J. Wort, S. British Thoracic, British Thoracic Society Clinical Statement on Pulmonary Arteriovenous Malformations, Thorax 72(12) (2017) 1154-1163.

7. C.L. Shovlin, J.E. Jackson, K.B. Bamford, I.H. Jenkins, A.R. Benjamin, H. Ramadan, E. Kulinskaya, Primary determinants of ischaemic stroke/brain abscess risks are independent of severity of pulmonary arteriovenous malformations in hereditary haemorrhagic telangiectasia, Thorax 63(3) (2008) 259-66.

8. M.E. Faughnan, V.A. Palda, G. Garcia-Tsao, U.W. Geisthoff, J. McDonald, D.D. Proctor, J. Spears, D.H. Brown, E. Buscarini, M.S. Chesnutt, V. Cottin, A. Ganguly, J.R. Gossage, A.E. Guttmacher, R.H. Hyland, S.J. Kennedy, J. Korzenik, J.J. Mager, A.P. Ozanne, J.F. Piccirillo, D. Picus, H. Plauchu, M.E. Porteous, R.E. Pyeritz, D.A. Ross, C. Sabba, K. Swanson, P. Terry, M.C. Wallace, C.J. Westermann, R.I. White, L.H. Young, R. Zarrabeitia, H.H.T.F.I.-G.W. Group, International guidelines for the diagnosis and management of hereditary haemorrhagic telangiectasia, Journal of medical genetics 48(2) (2011) 73-87.

9. C.L. Shovlin, E. Buscarini, A.D. Kjeldsen, H.J. Mager, C. Sabba, F. Droege, U. Geisthoff, S. Ugolini, S. Dupuis-Girod, European Reference Network For Rare Vascular Diseases (VASCERN) Outcome Measures For Hereditary Haemorrhagic Telangiectasia (HHT), Orphanet J Rare Dis 13(1) (2018) 136.

10. F.S. Govani, C.L. Shovlin, Hereditary haemorrhagic telangiectasia: a clinical and scientific review, European journal of human genetics : EJHG 17(7) (2009) 860-71.

11. K.K. Bundesvereinigung, Bonusheft. https://www.kzbv.de/bonusheft.39.de.html, (accessed 15.06.2020.).

12. M.W. Klingenberger D., Bonusregelung auf dem Prüfstand, zm 24 (2006) 18-19.

13. V.N. Iyer, W. Brinjikji, B.S. Pannu, D.R. Apala, G. Lanzino, H.J. Cloft, S. Misra, M.J. Krowka, C.P. Wood, K.L. Swanson, Effect of Center Volume on Outcomes in Hospitalized Patients With Hereditary Hemorrhagic Telangiectasia, Mayo Clin Proc 91(12) (2016) 1753-1760.

14. A. Kjeldsen, K.S. Aagaard, P.M. Torring, S. Moller, A. Green, 20-year follow-up study of Danish HHT patients-survival and causes of death, Orphanet J Rare Dis 11(1) (2016) 157.

15. F.H. Urban W. Geisthoff , Boris A. Stuck, Christina Grabowski, Freya Dröge, Leberabszess nach PZR, zm 108(12) (2018).

16. U. Geisthoff, Reminder: Früherkennungsprogramm zum Morbus Osler, zm 108(18) (2018) 59.

17. U. Geisthoff, Reminder: Früherkennungsprogramm zum Morbus Osler, 23 (18) (2018) 59.

18. U. Geisthoff, Morbus Osler, Apotheken Umschau (2016).

19. R.K.I. (RKI), Beiträge zur Gesundheitsberichterstattung des Bundes: Daten und Fakten: Ergebnisse der Studie Gesundheit in Deutschland aktuell 2009. 
<https://www.rki.de/DE/Content/Gesundheitsmonitoring/Gesundheitsberichterstattung/GBEDownloadsB/GEDA09.pdf? _blob=publicationFile>, 2011 (accessed 31.08.2020.).

20. A.R. Franziska Prütz, Inanspruchnahme ambulanter ärztlicher Versorgung in Deutschland, Journal of Health Monitoring 2(4) (2017) 88-94.

21. F. Droege, K. Thangavelu, B.A. Stuck, A. Stang, S. Lang, U. Geisthoff, Life expectancy and comorbidities in patients with hereditary hemorrhagic telangiectasia, Vasc Med (2018) $1358863 \times 18767761$.

22. A.E. Guttmacher, D.A. Marchuk, R.I. White, Jr., Hereditary hemorrhagic telangiectasia, N Engl J Med 333(14) (1995) 91824.

23. H. Plauchu, J.P. de Chadarevian, A. Bideau, J.M. Robert, Age-related clinical profile of hereditary hemorrhagic telangiectasia in an epidemiologically recruited population, American journal of medical genetics 32(3) (1989) 291-7.

24. S.R. Porter, V. Mercadante, S. Fedele, Oral manifestations of systemic disease, Br Dent J 223(9) (2017) 683-691.

25. A. Kuhne, J. Kleinheinz, J. Jackowski, J. Koppe, M. Hanisch, Study to Investigate the Knowledge of Rare Diseases among Dentists, Orthodontists, Periodontists, Oral Surgeons and Craniomaxillofacial Surgeons, Int J Environ Res Public Health 18(1) (2020).

26. OMIM - Online Catalog of Human Genes and Genetic Disorders. <www.ncbi.nlm.nih.gov/omim>, 2011).

27. F.D.I. (FDI), FDI Statement: Oral Cancer, FDI World 8(24) (1999).

28. J. McDonald, W. Wooderchak-Donahue, C. VanSant Webb, K. Whitehead, D.A. Stevenson, P. Bayrak-Toydemir, Hereditary hemorrhagic telangiectasia: genetics and molecular diagnostics in a new era, Front Genet 6 (2015) 1.

29. P.C. Edwards, "Considering that this is such a rare condition, should we really be expected to recognize it?", Oral Surg Oral Med Oral Pathol Oral Radiol Endod 112(2) (2011) 143-5.

30. M. McGurk, S.E. Scott, The reality of identifying early oral cancer in the general dental practice, Br Dent J 208(8) (2010) 347-51.

31. A.-S.C. Pierre-Etienne Chazal, Ségolène Aymé, Christian Deleuze, Diagnostic delay in rare diseases: a documented list of (296) rare diseases for which delayed diagnosis would be especially detrimental, based on the French situation, Research Square (2020).

32. Eurordis, The Voice of 12,000 patients: Experiences and Expectations of Rare Disease Patients on Diagnosis and Care in Europe. <https://www.eurordis.org/IMG/pdf/voice_12000_patients/EURORDISCARE_FULLBOOKr.pdf>, (accessed 31.08.2020.).

33. P. Pierucci, G.M. Lenato, P. Suppressa, P. Lastella, V. Triggiani, R. Valerio, M. Comelli, D. Salvante, A. Stella, N. Resta, G. Logroscino, F. Resta, C. Sabba, A long diagnostic delay in patients with Hereditary Haemorrhagic Telangiectasia: a questionnaire-based retrospective study, Orphanet J Rare Dis 7 (2012) 33.

34. E. de Vries, L. Fransen, M. van den Aker, B.R. Meijboom, Preventing gatekeeping delays in the diagnosis of rare diseases, Br J Gen Pract 68(668) (2018) 145-146.

35. T. Cellucci, S. Lee, F. Webster, Adapting Knowledge Translation Strategies for Rare Rheumatic Diseases, J Rheumatol 43(8) (2016) 1462-8.

36. K. Wittmeier, C. Holland, K. Hobbs-Murison, E. Crawford, C. Beauchamp, B. Milne, M. Morris, R. Keijzer, Analysis of a parent-initiated social media campaign for Hirschsprung's disease, J Med Internet Res 16(12) (2014) e288.

37. V.L. Resende, M.H. Abreu, S.M. Paiva, R. Teixeira, I.A. Pordeus, Concerns regarding hepatitis B vaccination and postvaccination test among Brazilian dentists, Virol J 7 (2010) 154.

38. I.C. Gadotti, C. Hulse, J. Vlassov, D. Sanders, D.A. Biasotto-Gonzalez, Dentists' Awareness of Physical Therapy in the Treatment of Temporomandibular Disorders: A Preliminary Study, Pain Res Manag 2018 (2018) 1563716.

39. A.H. Bati, A. Mandiracioglu, F. Govsa, O. Cam, Health anxiety and cyberchondria among Ege University health science students, Nurse Educ Today 71 (2018) 169-173. 
40. D. Svenstrup, H.L. Jorgensen, O. Winther, Rare disease diagnosis: A review of web search, social media and large-scale data-mining approaches, Rare Dis 3(1) (2015) e1083145.

41. S. Nickel, M. Haack, O. von dem Knesebeck, M.L. Dierks, G. Seidel, S. Werner, C. Kofahl, [Participation in self-help groups: impact on self-management and knowledge], Bundesgesundheitsblatt Gesundheitsforschung Gesundheitsschutz 62(1) (2019) 10-16.

42. M. Danner, C. Nachtigaller, A. Renner, [Evolution of health-related self-help. Experience from 40 years of work in selfhelp], Bundesgesundheitsblatt Gesundheitsforschung Gesundheitsschutz 52(1) (2009) 3-10.

43. D. Ärzteverlag, zm - Zahnärztliche Mitteilungen. <https://www.aerzteverlag.de/portfolio/fachwissen-medizindental/zmzahnaerztliche-mitteilungen/profil/>, (accessed 09.06.2020.).

\section{Figures}

\section{Figure 1}

Typical Telangiectasia of the skin and mucosa in a patient with HHT HHT = hereditary hemorrhagic telangiectasia 


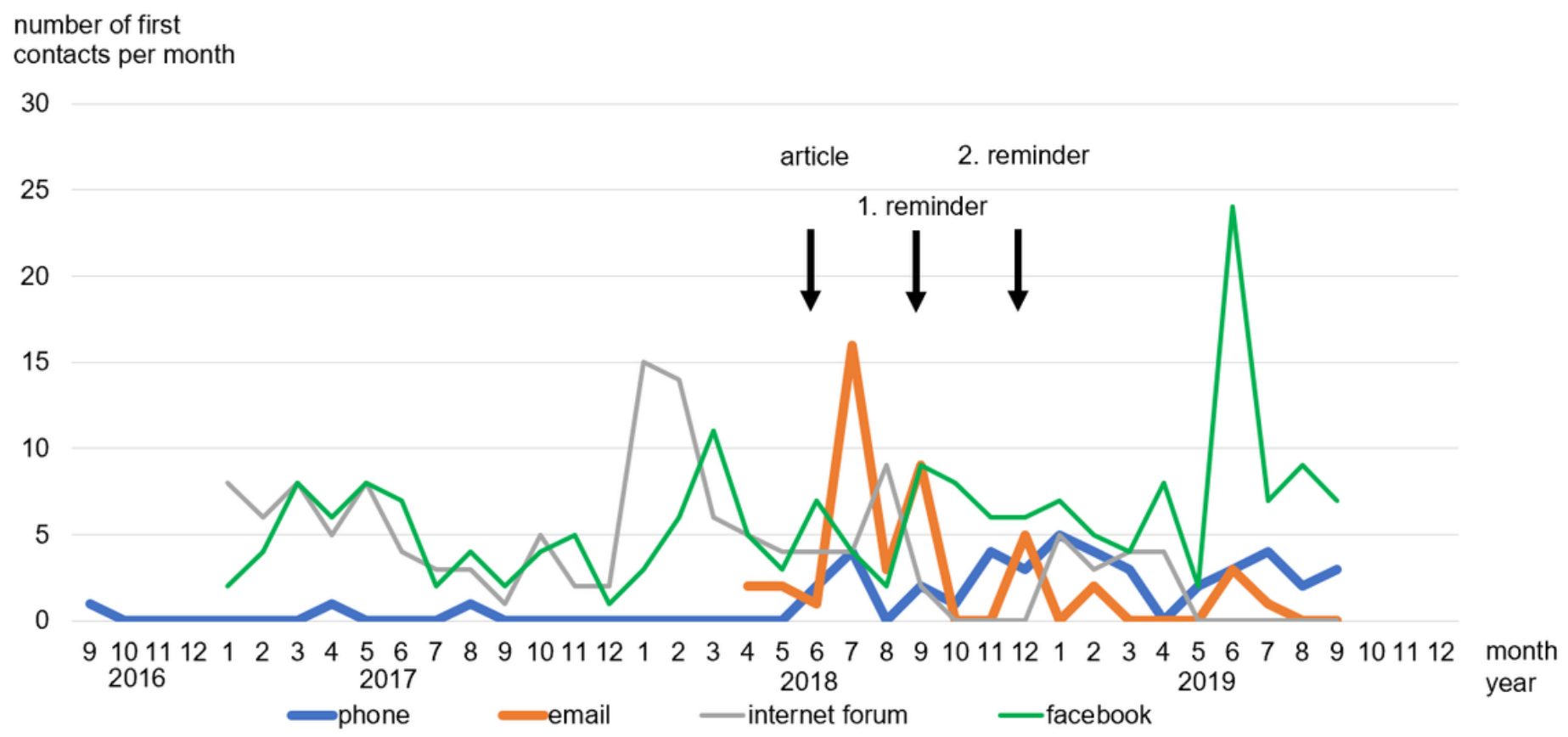

Figure 2

First contacts to the German self-help group per month Distribution of all 411 first contacts to the German self-help group from 09/2016 to 09/2019 by different communication channels and in relation to the publications of the awareness campaign. Due to mainly technical reasons the documentation for the whole period is only complete for first contacts by phone. The period of documentation is limited from 04/2018 - 09/2019 due to a hard drive problem of the self-help group in spring 2018. Documentation of the new contacts by internet forum and facebook $\circledast$ started in $1 / 2017$, however, it was stopped preterm for the internet forum due to a crash of the forum in spring 2018.

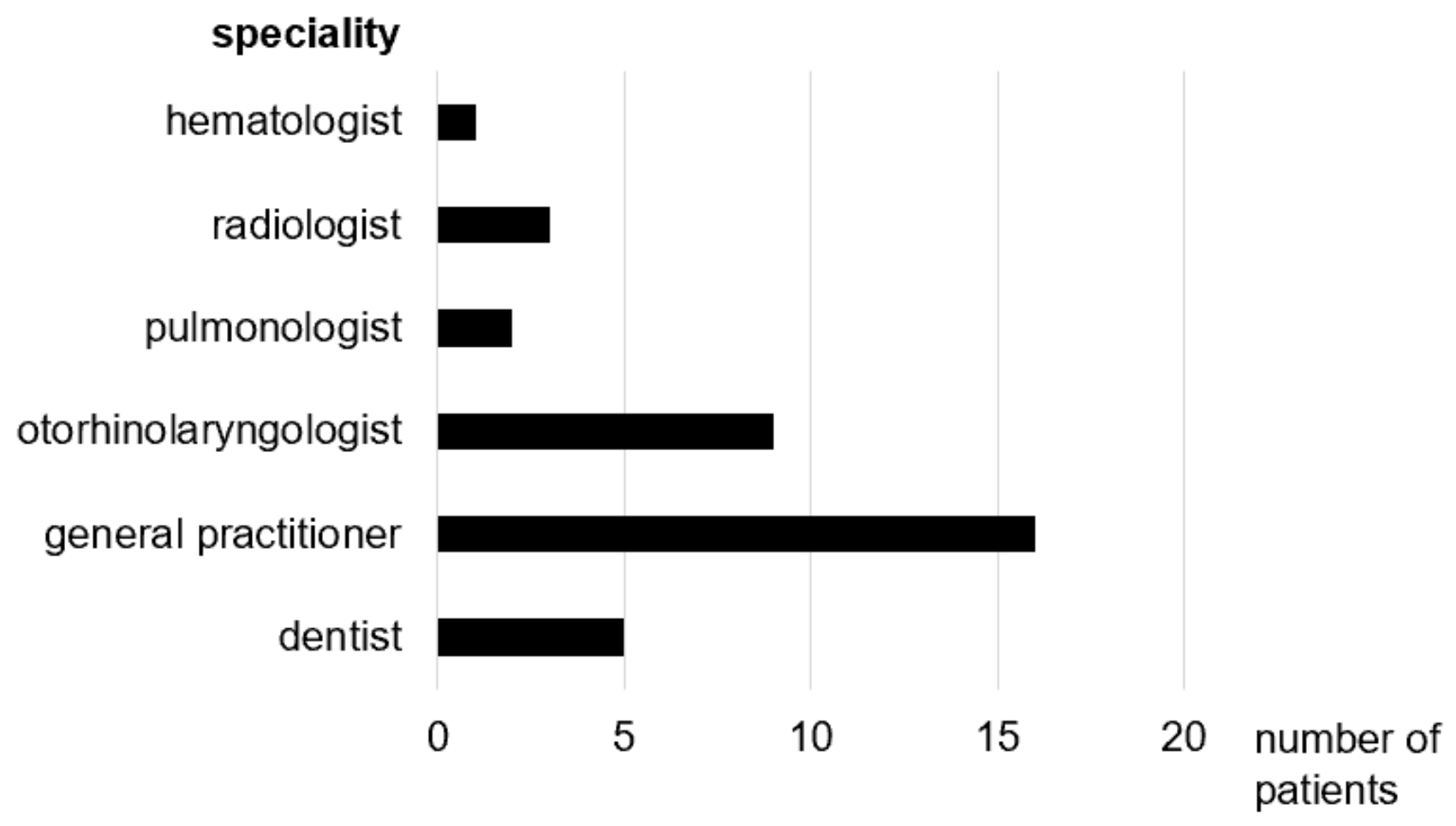




\section{Figure 3}

Different specialists referring patients with HHT to the German self-help group Data on referrals by physicians was only available for 36 of 411 contacts during the study time. Most patients received information about hereditary hemorrhagic telangiectasia (HHT) and the German self-help group via their general practitioner (number of patients $(\mathrm{N})=16 / 36,44 \%$ ) and otorhinolaryngologist $(\mathrm{N}=9 / 36,25 \%)$. In 5 patients their dentist recognizes the diagnosis $\mathrm{HHT}(\mathrm{N}=5 / 36,14 \%)$, all these 5 contacts occurred after the publication of the first article.
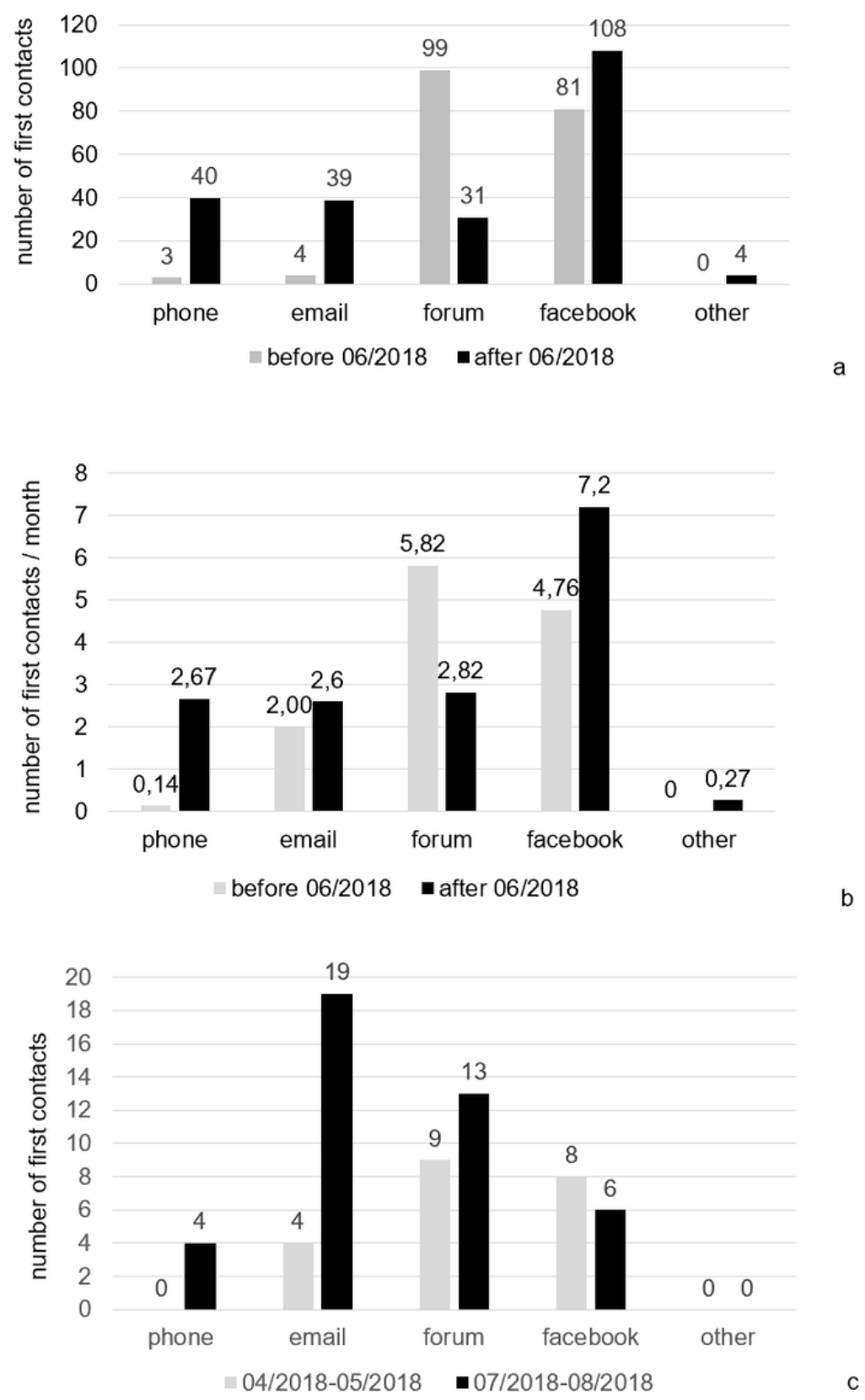

b

Figure 4

Number of first contacts via different communication channels for different calculations and time periods This graph shows the number of all first contacts documented between September 2016 and 2019 (a) and the average number of first contacts per months of documentation (b). Graph c demonstrates the number of contacts two months directly before and after publishing the initial article in June 2018 (c). In total 4 patients got into contact with the German self-help group via other communication channels ("other": $2 x$ via the facebook ${ }^{\circledR}$ homepage of the self-help group for patients with pulmonary 
hypertension, $1 \mathrm{x}$ indirect via friends who were contacting the German self-help group via facebook® and $1 \mathrm{x}$ directly via the general practitioner) 